\title{
Whole-Body Counter, Marcus Whitman Elementary
}

The mobility of this new laboratory provides versatile capabilities for measuring internally deposited gamma-ray emitting radionuclides in human beings.

-Health Physics, November 1965

We were warned to shut our eyes. Everyone was school-age now, our kindergarten teacher reminded us,

old enough to follow directions and do a little for our country. My turn came and the scientists

strapped me in and a steady voice prompted The counter won't hurt, lie perfectly still, and mostly I did

and imagined what children pretend America is, parks bordered by feathery evergreens,

lawns so green and lush they soothe the eyes and pupils open like love-

a whole country of lawns like that. Just once I peeked and the machine had taken me in

like a spaceship and I moved slow as the sun through the chamber's smooth steel sky.

I shut my eyes again, pledged to be still; how proud I was to be a girl America could count on. 